\title{
A Financial Model to Determine the Distortions in Economic Value Added (EVA) Caused by Inflation
}

\author{
J U de Villiers
}

Department of Business Management, University of Stellenbosch

\section{ABSTRACT}

This paper presents an algebraic model to study the extent to which inflation distorts Economic Value Added (EVA). The model consists of a theoretical firm in steady state, consisting entirely of projects with the same known internal rate of return. The EVA this firm reports is then calculated, and compared to the true economic profit calculated from the known return of the firm. The model shows that both conventional EVA and EVA based on the current value of assets are distorted by inflation. The distortion in the latter is more systematic, and this could form the basis of an adjusted EVA calculation to provide an estimate actual profitability.

JEL E 31

\section{INTRODUCTION}

Economic value added (EVA) is a new name for an old concept, economic profit. Economic profit is the revenue generated by a firm after the cost of the capital it employs has been taken into account. Stewart (1991) called this economic value added (and abbreviated it to EVA, a term subsequently registered as a trademark by the firm Stern Stewart \& Co). Stewart formalised the calculation of EVA and advocated its wide use in financial decision making. $\mathrm{He}$ recommends that managers should aim to maximise EVA instead of maximising profits, and that EVA should be used for "setting goals, evaluating performance, determining bonuses, communicating with investors, and for capital budgeting and valuations of all sorts" (Stewart 1991: 4).

EVA is based on accounting profit. It is well known that the accounting return a firm reports is often a poor proxy for its true return. This discrepancy between accounting and true retum is exacerbated by inflation. EVA will be distorted by inflation too. De Villiers (1997) studied this distortion and found that inflation distorts EVA to such an extent that it cannot be used under inflation to estimate 
actual profitability. De Villiers (1997: 289-91) provided a numerical example to show the distortions. The present paper provides the more general algebraic model to derive the relationships between the true return of a firm and the EVA it reports.

The basis of the model is the construction of a theoretical firm in steady state, made up entirely of projects with the same known internal rate of return. The return of the firm is known, since it is equal to the internal rate of return of the projects that comprise the firm. The EVA that this firm will report under various circumstances can then be calculated. This is compared to the true economic profit to determine the distortion in reported EVA. The true economic profit is known because the true return of the firm is known.

This technique (constructing theoretical firms of known return and calculating the accounting figures the firms will report under various circumstances) was first used by Harcourt (1965) to study the relationship between accounting retum and true returm. It has since become a standard method used in many studies [see De Villiers (1997) for an overview].

The model to study the distortion in EVA under inflation is presented below in four sections. After the Introduction, the second section specifies the cash flows of the projects comprising the theoretical firm. This includes calculating the annual trading surplus that will give a project a particular internal rate of retum. The third section then determines the EVA reported by the theoretical firm. To do this, it calculates the net operating profit after tax that the theoretical firm reports, and the book value of the assets of this firm. These are then used to calculate the EVA that the firm reports, and to compare this to the known true economic profit. The fourth section focuses on EVA based on the current value of assets. It determines the current value of assets and then uses this in the EVA calculation, again comparing to the known true economic profit to determine distortions. The fifth section concludes the paper.

The model presented below comprises a theoretical firm consisting of a number of projects. The variables that are used to describe the firm and its projects refer to activity during a year or balance at the end of a year, as applicable. S, for example, refers to sales during a year, and $C$ refers to creditors at the end of a year.

It is necessary to distinguish between variables relating to individual projects and variables relating to the firm, and single or double subscripts are used to do this. Double subscripts indicate a project variable; the first subscript relating to the year of the project and the second to the year the project was initiated. $S_{2,3}$, for example, is the project sales during the second year of a project started in 
year 3 , and $\mathrm{C}_{4,1}$ the project creditors at the end of the fourth year of a project started in year 1 . A single subscript refers to a variable relating to the firm as a whole. Thus, $S_{5}$ is the total sales by the firm in year 5 , and $C_{1}$ is the sum of the creditors of the firm at the end of year 1 . The variables themselves will be defined as they are introduced.

\section{PROJECT CASH FLOWS}

Each individual project consists of an initial investment in current, depreciable and non-depreciable assets. The project runs for $d$ years in which the annual turnover, expenses, and cost of goods sold stay constant in real terms. In these subsequent years no investment is made in depreciable or non-depreciable assets. Current assets employed increase in nominal terms in line with the nominal increase in turnover, and this requires an annual investment in current assets. At the end of the project the depreciable assets are taken to have zero scrap value. Current assets and non-depreciable assets have wound-up values equal to the initial investment in real terms.

In any year $n$ of the project initiated in year $k$, the annual cash flow $\left(F_{n, k}\right)$ consists of the cash received minus the cash paid out during that year. The cash received consists of payments for goods sold, and is equal to the annual sales $\left(S_{n, k}\right)$ minus sales on credit not yet paid for (debtors added during the year, $D_{n, k}^{A}$ ) plus the payments received from the sales on credit during the previous years (debtors that paid during the year, $D_{n, k}^{P}$ ).

The cash payments in any year $n$ consists of payments to purchase inventory, cash expenses incurred during the year $\left(X_{n, k}\right)$, depreciable assets acquired during the year $\left(D A_{n, k}^{A}\right)$, non-depreciable assets acquired during the year $\left(N A_{n, k}^{A}\right)$, and tax payments made during the year $\left(T_{n, k}\right)$. The payments to purchase inventory are equal to the amount of inventory acquired $\left(I_{n, k}^{A}\right)$, minus the purchases on credit not yet paid (creditors added during the year, $C_{n, k}^{A}$ ) plus payments for inventory previously purchased (creditors paid during the year, $C_{n, k}^{F}$ ).

The total annual cash flow in any year $n$ of the project initiated in any year $k$ can therefore be expressed as:

$F_{n, k}=\left(S_{n, k}-D_{n, k}^{p}+D_{n, k}^{p}\right)-\left(I_{n, k}^{A}-C_{n, k}^{A}+C_{n, k}^{p}\right)-X_{n, k}-D A_{n, k}^{A}-N A_{n, k}^{A}-T_{n, k}$

The firm is assumed to pay income tax on its accounting profits at a rate of $t$. Taxable income is calculated according to historical cost conventions, and the 
$\operatorname{tax}$ is assumed to be payable immediately. The model assumes that no capital gains tax applies. In any year $n$ of the project started in year $k$, the taxable income of the firm equals annual sales $\left(S_{n, k}\right)$ minus the deductible expenses. Tax deductible expenses consist of the cash expenses $\left(X_{n, k}\right)$, the inventory processed $\left(I_{n, k}^{p}\right)$, and the depreciation of depreciable assets $\left(D A_{n, k}^{D}\right)$. The tax is payable at a rate $t$, and therefore:

$T_{n, k}=t\left(S_{n, k}-X_{n, k}-I_{n, k}^{P}-D A_{n, k}^{D}\right)$

During any year $n$ of the project the amount of debtors at the end of the year is equal to the debtors at the beginning of the year plus the debtors added during the year minus debtors that paid during the year, so that:

$D_{n, k}=D_{n-1, k}+D_{n, k}^{A}-D_{n, k}^{p}$

Similarly for creditors and inventory:

$C_{n, k}=C_{n-1, k}+C_{n, k}^{A}-C_{n, k}^{P}$

$I_{n, k}=I_{n-1, k}+I_{n, k}^{A}-I_{n, k}^{P}$

The model assumes that the project is initiated in year 0 and operates for $d$ years until it is terminated in year $d$. We shall first analyse the cash flows in year 0 of the project, then analyse the cash flows in any of the subsequent years of the project (except the last year), and finally analyse the cash flows in the last year of the project.

\subsection{First Year of the Project}

In year 0 of the project (the year in which the project is initiated) no sales take place, no cash expenses are incurred, and no inventory is processed. Therefore: $S_{0, k}=X_{0, k}=I_{0, k}^{P}=0$

No debtors, creditors or inventory exist before the project is initiated, and therefore:

$D_{-1, k}=C_{-i, k}=I_{-1, k}=0$

If these are substituted into equation (3), and the resulting relationships rearranged and substituted into equations (2) and (1), then the cash flow in year 0 is:

$F_{0, k}=-C A_{0, k}-D A_{0, k}^{A}-N A_{0, k}^{A}$

where $C A_{0, k}$ (the current assets at the end of year 0 ) consist of the debtors plus inventory minus creditors at the end of year 0 . 


\subsection{Subsequent Years of the Project}

We now proceed to analyse the cash flows in the subsequent years of the project (except the last year, which will follow later). In these subsequent years no investment is made in depreciable or non-depreciable assets. For any year $j$ of the project (where $0<j<d$ ):

$$
D A_{j, k}^{A}=N A_{j, k}^{A}=0
$$

Furthermore, because of the regular trading pattern debtors stay constant in real terms for the duration of the project. The debtors at the end of any year are therefore $(1+i)$ times the debtors at the end of the year before. For year $j$, therefore:

$$
D_{j, k}=(1+i) D_{j-1, k}
$$

so that, by substituting into (3):

$$
D_{j, k}^{A}=i D_{j-i, k}-D_{j, k}^{P}
$$

Because the trading pattern stays constant in real terms, the debtors at the end of any year are equal to the debtors at the end of year 0 increased by the rate of inflation. For year $(j-1)$, therefore:

$$
D_{j+1, k}=(1+i)^{j-1} D_{0, k}
$$

Substituting into the equation above:

$$
D_{j, k}^{A}=i(1+i)^{j-1} D_{0, k}-D_{j, k}^{p}
$$

Similarly for creditors and inventory:

$$
\begin{aligned}
& C_{j, k}^{A}=i(1+i)^{j-1} C_{0, k}-C_{j, k}^{P} \\
& I_{j, k}^{A}=i(1+i)^{j-1} I_{0, k}-I_{j, k}^{P}
\end{aligned}
$$

The cash flow in any year $j\left(F_{j, k}\right)$ can then be calculated by substituing into equations (1) and (2) from the above for debtors added $\left(D_{, k, k}^{A}\right)$, creditors added $\left(C_{j, k}^{A}\right)$, and inventory acquired $\left(I_{j, k}^{A}\right)$, and by substiting from equation $(5)$ for 
depreciable assets acquired $\left(D A_{j, k}^{A}\right)$ and non-depreciable assets acquired $\left(N A_{j, k}^{\hat{A}}\right)$, and then substituting (2) into (1), to leave (after rearranging):

$$
F_{j, k}=S_{j, k}-X_{j, k}-I_{j, k}^{p}-i(1+i)^{j-1} C A_{0, k}-t\left(S_{j, k}-X_{j, k}-I_{j, k}^{p}-D A_{j, k}^{D}\right)
$$

For simplicity we combine sales, cash expenses and inventory processed into a single variable we call the trading surplus $\left(T S_{j, k}\right)$. This is defined as the sales minus cash expenses minus value of inventory processed. Because of the regular trading patttern we assumed, the sales, cash expenses and inventory stay constant in real terms and therefore increase by the rate of inflation in nominal terms. So does the trading surplus, and therefore:

$$
S_{j, k}-X_{j, k}-I_{j, k}^{P}=T S_{j, k}=(1+i)^{j-1} T S_{l, k}
$$

Furthermore, because of straight line depreciation and the fact that all depreciable assets are purchased in year 0 of the project:

$D A_{j, k}^{D}=\frac{D A_{0, k}^{A}}{d}$

So that, after substituting (7) and (8) into (6):

$$
F_{j, k}=(1-t)(1+i)^{j-1} T S_{1, k}-i(1+i)^{j-1} C A_{0, k}+\frac{t}{d} D A_{0, k}^{A}
$$

Equation (9) shows that the annual project cash flow cash consists of three elements: the annual trading surplus, an additional investment in current assets to keep pace with inflation, and the depreciation tax shield.

\subsection{Last Year of the Project}

We now proceed to analyse the cash flows in the last year of the project (year $d$ ). The cash flows from the trading surplus, the additional investment in current assets, and the depreciation tax shield are calculated in the same way as for the preceding years. In addition, positive cash flows from the wound-up values of non-depreciable assets and current assets have to be taken into account. The level of current assets grows and the value of non-depreciable assets increases at the rate of inflation. After adding these to the amounts in equation (9), we obtain:

$$
F_{d, k}=(1-t)(1+i)^{d-1} T S_{1, k}-i(1+i)^{d-1} C A_{0, k}+\frac{t}{d} D A_{0, k}^{A}+(1+i)^{d}\left(C A_{0, k}+N A_{0, k}^{A}\right)
$$

The cash flow in any year of the project can therefore be determined from one of equations (4), (9), and (10) above. 


\subsection{First Year Trading Surplus Required}

To construct a firm with a known true return, all the projects making up the firm must have the same internal rate of retum. We therefore have to determine the project characteristics that will yield the specified internal rate of retum. More specifically, our aim is to determine what the project's trading surplus has to be to yield the required internal rate of return.

The internal rate of return of the project depends on the cash flows specified in equations (4), (9), and (10) above. The trading surplus required to provide a particular internal rate of return can be determined by calculating the present values of the annual cash flows, making the sum of the present values equal to zero and solving for the trading surplus.

If the project has an internal rate of return (in nominal terms) of $r$, then the net present value of the project cash flows (discounted at the rate of r) equals zero, or:

$\sum_{j=0}^{d} \frac{F_{j, k}}{(1+r)^{j}}=0$

Substituting from equations (4), (9) and (10) for the annual cash flows, solving for $T S_{i, k}$ and simplifying, yields:

$T S_{1, k}=\left(\frac{r}{1-i}\right) C A_{0, k}+\left(\frac{r-i}{1-i}\right)\left(\frac{1-\frac{t}{d r}\left(1-\left(\frac{1}{1+r}\right)^{d}\right)}{1-\left(\frac{1+i}{1+r}\right)^{\alpha}}\right) D A_{0, k}^{A}+\left(\frac{r-i}{1-i}\right) N A_{0, k}^{A}$

Equation (11) specifies the first year's trading surplus required to yield the internal rate of return $(r)$. This can be used to substitute for $T S_{l, k}$ in equations (9), and (10). Using equations (4), (9), (10) and (11) it is therefore possible to specify all the cash flows of a project from its initial investment in current, depreciable and non-depreciable assets, the project duration, its internal rate of return, the tax rate, and the inflation rate. This will be used in the following section to calculate the EVA reported by a firm made up from these projects.

\section{ECONOMIC VALUE ADDED (EVA) REPORTED BY THE FIRM}

Until now, we have focused on the cash flows of the projects comprising the firm. From now on we shall focus upon establishing the characteristics of the 
firm made up of these projects. This requires summation across the current projects of the firm.

To calculate the EVA requires calculating the net operating profit after tax (NOPAT) reported by the firm, and the assets employed by the firm. These will be determined in tum below, and then used to calculate reported EVA

\subsection{Calculating the Net Operating Profit after Tax}

The net operating profit after tax reported by the firm is determined first, by, calculating the profit before tax and, then, subtracting the tax payable. To calculate the accounting profit of the firm requires summation across the current projects of the firm. The firm consists of $(d+1)$ projects, each with an operating life of d years. One of the projects is just being started, one project is in its first year of operation, one in its second year of operation and so forth until the oldest project in its last (dth) year of operation. In the absence of real growth, each project is equally large in real terms and $(1+i)$ times larger in nominal terms than the project started one year earlier (where $i$ is the rate of inflation). Once steady state is reached, a firm will terminate its oldest project and start a new project every year.

We shall calculate the NOPAT generated by the firm in year $(k+1)$, which is the first year in which the project started in year $k$ will be in operation. We therefore calculate the accounting profit reported by the firm in year $(k+1)$ (eamings reported in year $\left.(k+1), E_{k+1}\right)$. This consists of the total sales in that year $\left(S_{k+1}\right)$ minus the cash expenses $\left(X_{k+1}\right)$, inventory processed $\left(I_{k+1}^{P}\right)$, and the depreciation reported (assets depreciated, $D A_{k+1}^{\mathcal{D}}$ ), so that:

$$
E_{k+1}=S_{k+1}-X_{k+1}-I_{k+1}^{P}-D A_{k+1}^{D}
$$

For simplicity, we have earlier combined the first three variables into a single variable called the trading surplus, or:

$S_{k+1}-X_{k+1}-I_{k+1}^{P}=T S_{k+1}$

and therefore:

$$
E_{k+1}=T S_{k+1}-D A_{k+1}^{D}
$$


The firm consists of its current projects. In year $k+1$, the project initiated in year $k+1$ has not yet started to generate any tumover. The current projects generating turnover are therefore the $d$ projects initiated in the $d$ years prior to year $k+1$. By separating the earnings components into the contributions from each of the current projects, it expands to:

$$
E_{k+1}=\sum_{j=1}^{d} T S_{j, k-(j-1)}-\sum_{j=1}^{d} \frac{D A_{0, k-(j-1)}^{A}}{d}
$$

Because all three elements of the trading surplus of each project stay constant in real terms over the duration of the project, the trading surplus in any year is equal to the trading surplus in year 1 of that project, increased by the rate of inflation, or:

$$
T S_{i, k-(j-1)}=(1+i)^{j-1} T S_{i, k-(j-1)}
$$

Furthermore, because each project is as large (in real terms) as the project started a year before, the first year trading surplus of any project is $(1+i)$ times larger than the first year first year trading surplus of the project started a year earlier. This increase is compound when compared to the first year turnover of earlier projects. Therefore:

$T S_{1, k-(1-1)}=\frac{T S_{1, k}}{(1+i)}$

and, from (14) and (15):

$T S_{j, k-(j-1)}=T S_{1, k}$

The value of depreciable assets acquired by projects in successive years increase by the rate of inflation, and therefore:

$$
D A_{0, k-\{j-1)}^{A}=\frac{D A_{0, k}^{A}}{(1+i)^{-1}}
$$

So that, after substituting (17) and (16) into (13):

$$
E_{k+1}=d T S_{1 . k}-\frac{D A_{0 . k}^{A}}{d} \sum_{j=1}^{d} \frac{1}{(1+i)^{j-1}}
$$

The EVA calculation requires the calculation of the net operating profit after tax (NOPAT). Stewart (1991) suggests numerous adjustments to profits when calculating NOPAT. None of these adjustments apply to the simplified model 
used in this analysis. Tax at a rate $t$ is payable on the earnings figure, and the NOPAT of the firm is therefore simply the earnings calculated in equation (18) multiplied by $(1-t)$. After multiplying by $(1-t)$, summing the series, substituting from (11) for $T S_{l, k}$, gathering terms, and simplifying:

$$
\begin{aligned}
& N O P A T_{k+1}=d \cdot r . C A_{0, k} \\
& \begin{array}{l}
+\left[d(r-i)\left(\frac{1-\frac{t}{d . r}\left(1-\left(\frac{1}{1+r}\right)^{d}\right)}{1-\left(\frac{1+i}{1+r}\right)^{d}}\right)-(1-i)\left(\frac{1+i}{d i}\right)\left(1-\left(\frac{1}{1+i}\right)^{d}\right)\right] D A_{0, k}^{A} \\
+\left(\frac{d(r-i)}{1-i}\right) N A_{0, k}^{A}
\end{array}
\end{aligned}
$$

\subsection{Calculating Book Value of Assets}

Calculating EVA also requires the calculation of the assets employed by the firm. The book value of the assets is calculated by summation across all the current projects of the firm. Current and non-depreciable assets are valued at cost. Straight-line depreciation over the total life of the assets is employed to calculate the book value of depreciable assets.

The book value of the firm at the end of year $k$ is equal to the book value of the current, depreciable and non-depreciable assets of the firm, or:

$$
A_{k}=C A_{k}+D A_{k}+N A_{k}
$$

Separating this into the contributions of each of the current projects of the firm:

$$
A_{k}=\sum_{j=0}^{d-1} C A_{j, k-j}+\sum_{j=0}^{j=1}\left(\frac{d-j}{d}\right) D A_{0, k-j}^{A}+\sum_{j=0}^{d-1} N A_{0, k-j}^{A}
$$

The current assets employed by projects increase annually at the rate of inflation, and the projects themselves increase in size also at the rate of inflation. Therefore:

$$
C A_{j, k-j}=C A_{0, k}
$$

The projects increase in size at the rate of inflation, and therefore: 
$D A_{0, k-j}^{A}=\frac{D A_{0, k}^{A}}{(1+i)^{j}}$ and $N A_{0, k-j}^{A}=\frac{N A_{0, k}^{A}}{(1+i)^{\prime}}$

Substituting into (20), summing the series, and simplifying:

$$
A_{k}=d C A_{0, k}+\left[\left(\frac{1+i}{i}\right)-\left(\frac{1+i}{d, i^{2}}\right)+\left(\frac{1}{d i^{2} \cdot(1+i)^{d-1}}\right)\right] D A_{0, k}^{A}+\left[\left(\frac{1+i}{i}\right)\left(1-\left(\frac{1}{1+i}\right)^{d}\right)\right] N A_{0, k}^{A}
$$

\subsection{Calculating EVA}

The model assumes a firm in steady state, and the Standardised EVA the firm reports would be the same in any year (once steady state is reached). We calculate the Standardised EVA reported by the theoretical firm in year $k+1$, the first year in which the project initiated in year $k$ will be operational. Given steady state, it would not have made a difference if we chose any other year.

The capital value on which the EVA calculation is based, is the assets employed by the theoretical firm at the beginning of year $k+1$, which is the same as the assets employed at the end of year $k$. The EVA reported by the firm is therefore equal to:

$$
E V A_{k+1}=N O P A T_{k+1}-c^{*} A_{k}
$$

where $c^{*}$ is the cost of capital of the firm, and $N O P A T_{k+1}$ and $A_{k}$ can be determined from equations (19) and (21) respectively.

To calculate the standardised EVA (SEVA), divide the EVA in equation (22) by $A_{k}$ and multiply by 100 , so that:

$S E V A_{k+1}=100\left(\frac{N O P A T_{k+1}}{A_{k}}-c^{*}\right)$

where NOPAT $T_{k+1}$ and $A_{k}$ can be determined from equations (19) and (21) respectively.

\subsection{Distortion in EVA}

To study the distortion in Standardised EVA, we shall use equations (19), (21) and (23) to calculate the Standardised EVA reported by a specific firm, employing a specific type of asset and with a specific true rate of return, inflation rate, and tax rate. We can then compare the reported EVA to the true 
economic profit, which can be calculated from the known true retum. The difference between the two figures shows the extent to which EVA is distorted by inflation.

The distortion in EVA depends upon the type of assets employed by the firm. One way of studying the pattern of distortions is to consider firms employing only one type of asset. Five such firms are considered below. The first is a firm that employs only current assets (for example, a small retail operation renting the fixed assets it requires). We also consider three firms that employ only depreciable assets (for example, machinery in manufacturing operations). They consist of a firm employing depreciable assets with a life of four years, a firm employing depreciable assets with a life of years, and a firm employing only depreciable assets with a life of twenty years. The fifth firm considered is one that employs only non-depreciable assets (for example, land as its only asset).

Figure 1 shows the Standardised Economic Value Added these firms will report under different rates of inflation. Each of the firms has a real return of 10 percent per year and a real cost of capital of 10 percent per year. The firms therefore all make zero economic profit, and should report a Standardised Economic Value Added of zero. The extent to which the reported Standardised Economic Value Added differs from zero, shows the extent to which this has been distorted.

Figure 1 shows that reported EVA is distorted, even in the absence of inflation. At zero inflation the current asset firm and the non-depreciable asset firms report the correct EVA ( 0 per cent). The other three firms report EVA of 0.5 per cent (firm with 4 year assets) 1.4 per cent (firm with 10 year assets) and 2.8 per cent (firm with 20 year assets) respectively. This distortion stems from the use of straight-line depreciation, which differs from economic depreciation, even in the absence of inflation.

Figure 1 further shows that this distortion in reported EVA is exacerbated by inflation. It is only the firm exclusively employing current assets that reports the correct EVA ( 0 per cent). The reported EVAs of all the other firms are distorted, including that of the firm exclusively employing non-depreciable assets. For all these firms, the distortions increase with increasing inflation. At an inflation rate of 10 per cent, the three firms employing depreciable assets report EVA of 1.6 per cent (firm with 4 year assets) 5.3 per cent (firm with 10 year assets) and 12.5 per cent (firm with 20 year assets) respectively. The firm employing nondepreciable assets reports an EVA of 2.5 per cent. 
Figure 1 Standardised Economic Value Added reported by a firm with a real return of 10 per cent per year and a real cost of capital of 10 per cent per year

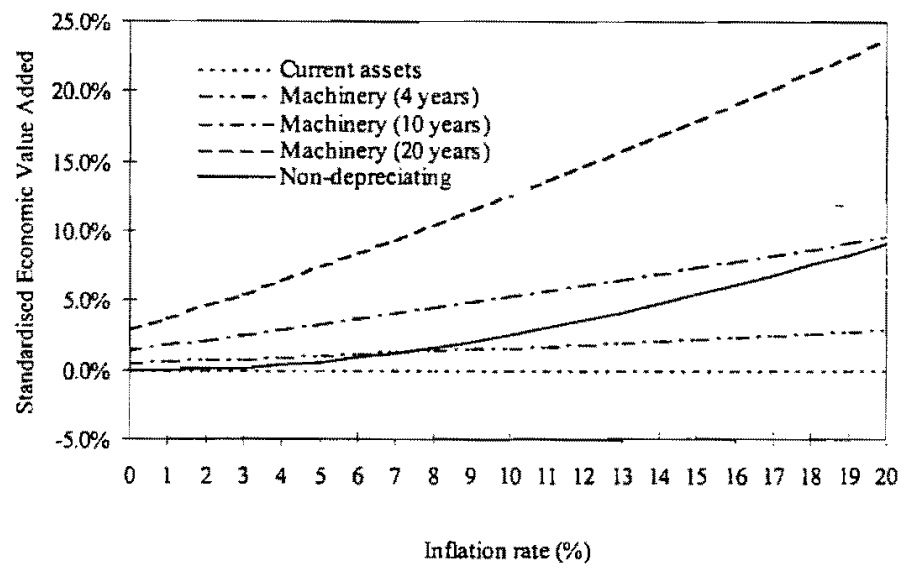

It is clear from the illustrative figures above that the distortion in EVA caused by inflation is large. Unless this distortion can be compensated for, reported EVA cannot be used under inflation to estimate actual profitability. To compensate for the distortion, it is necessary to understand the pattern of the distortion. This is difficult, because the distortion illustrated in Figure 1 is caused by distortions in both the profit and the asset figures used in the EVA calculation. To understand the contributions of the two underlying distortions requires for the researcher to be able to separate their effects. The model must be expanded to include a study of the effect of inflation on the reported asset values. This is undertaken below.

\section{ECONOMIC VALUE ADDED BASED ON CURRENT VALUE OF ASSETS}

To separate the effects of a distortion in profits from a distortion in asset values, De Villiers (1997) recommends that EVA calculations be based on the current value of assets (as opposed to the historical value conventionally used). This reduces the distortion in EVA to that part of the distortion caused by the distortion in the accounting profit figure, and makes the pattern of the distortion 
easier to interpret. De Villiers (1997) illustrates this by means of a numerical example. We now expand the more general model above to present an algebraic derivation of the relationship between the true return of the firm and the EVA based on the current value of assets.

\subsection{Calculating the Current Value of Assets Employed by a Project}

To determine the current value of assets, this analysis is related to on the future cash flow these assets will generate. In the model of the firm employed here, the future cash flows of all projects are known. It is therefore possible to determine the value of the assets employed for each project or for the firm (the combination of its current projects), by discounting and summing across the future cash flows.

When determining the current value of the assets, the present analysis aims to exclude the increase in the value of assets that results from superior investments. It therefore calculates what the current value of the assets employed by the firm would have been if employed in an application that yields the firm's cost of capital. The value of the assets does therefore not increase as a result of deriving returns higher than the cost of capital.

The procedure is therefore as follows. Estimate the cash flows that would be associated with a marginal firm investing in marginal projects. The capital employed by the firm is then the present value of the remaining cash flows of the current projects employed by this firm. The net present value of every completed project of the marginal firm equals zero. The future projects of the marginal firm do therefore not add to its current value, and do not have to be taken into account.

The cash flows of the remaining projects of the hypothetical marginal firm can be determined from equations (9) and (10) (the annual cash flows) as well as equation (11) (the trading surplus required to yield a specified return). Since this is a marginal firm, we substitute the cost of capital $\left(c^{*}\right)$ for the return on the projects of the firm $(r)$ in equation (11).

The value of the remaining cash flows of a project that was initiated in year $k$, at the end of $j$ years is:

$V_{j, k}=\sum_{m=j+1}^{d} \frac{F_{m, k}}{\left(1+c^{\cdot}\right)^{m-j}}$ 
Using (9) and (10) to substitute for $F_{m, k}$ in the equation above, and then using (11) (after substituting $c^{*}$ for $r$ in equation (11)), to substitute for $T S_{1, k}$, this yields (after summing the series and simplifying):

$$
\begin{aligned}
& V_{i, k}=(1+i)^{j} C A_{0, k} \\
& +\left[\frac{t}{d \cdot c^{*}}\left\{1-\left(\frac{1}{1+c^{*}}\right)^{d-j}\right\}+\frac{(1+i)^{j}\left\{1-\frac{t}{d c^{*}}\left(1-\left(\frac{1}{1+c^{*}}\right)^{d}\right)\right\}\left[1-\left(\frac{1+i}{1+c^{*}}\right)^{d-j}\right\}}{1-\left(\frac{1+i}{1+c^{*}}\right)^{j}}\right] D A_{0, k}^{A} \\
& +(1+i)^{j} N A_{0, k}^{A}
\end{aligned}
$$

\subsection{Calculating the Current Value of Assets Employed by the Firm}

The value of the firm is the sum of the value of all its current projects, or:

$V_{k}=\sum_{m=0}^{d-1} V_{m, k-m}$

Substituting for the values of the individual projects from (25) we obtain an expression for the value of the firm in terms of the current assets, depreciable assets and non-depreciable assets at the end of the initial years of each of the firm's current projects.

But:

$C A_{0, k-m}=\frac{C A_{0, k}}{(1+i)^{m}}, \quad D A_{0, k-m}^{A}=\frac{D A_{0, k}^{A}}{(1+i)^{m}}$ and $\quad N A_{0, k-m}^{A}=\frac{N A_{0, k}^{A}}{(1+i)^{m}}$

Substituting into the above, we obtain an expression for the value of the firm in terms of the current, depreciable and non-depreciable assets at the end of the initial year of the project started in year $k$. After summing the series and simplifying, this yields:

$$
\begin{aligned}
V_{k}= & d \cdot C A_{0, k} \\
& +\left[\frac{t}{d c^{*}}\left\{\frac{1+i}{i}\left(1-\frac{1}{(1+i)^{d}}\right)-\frac{1+i}{c^{*}-i}\left(\frac{1}{(1+i)^{d}}-\frac{1}{\left(1+c^{*}\right)^{d}}\right)\right\}\right. \\
& \left.+\left\{1-\frac{t}{d \cdot c^{*}}\left(1-\frac{1}{\left(1+c^{*}\right)^{d}}\right)\right]\left\{\frac{d}{1-\left((1+i) /\left(1+c^{*}\right)\right)^{d}}-\frac{1+i}{c^{*}-i}\right\}\right] D A_{0, k}^{A} \\
& +d \cdot N A_{0, k}^{A}
\end{aligned}
$$




\subsection{Calculating EVA Based on Current Value of Assets}

The EVA based on the current value of assets $\left(E V A^{C}\right)$ is calculated in the same way as EVA on the book value of assets in (22), except that $V_{k}$ is used instead of $A_{k}$ as the asset base, so that:

$$
E V A_{k+1}^{C}=N O P A T_{k+1}-c^{*} V_{k}
$$

where NOPAT $T_{k+1}$ and $V_{k}$ can be determined from equations (19) and (26) respectively.

To calculate the standardised EVA based on current value of assets (SEVA ${ }^{\mathrm{C}}$ ), divide the EVA in equation (22) by $V_{k}$ and multiply by 100 , so that:

$$
S E V A_{k+1}^{c}=100\left(\frac{N O P A T_{k+1}}{V_{k}}-c^{*}\right)
$$

where NOPAT $T_{k+1}$ and $V_{k}$ can be determined from equations (19) and (26) respectively.

\subsection{Distortion in EVA Based on Current Value of Assets}

To study the distortion in Standardised EVA based on current value of assets, we shall use equations (19), (26) and (28) to calculate the Standardised EVA reported by a specific firm. In a similar analysis as the one employed previously to analyse the distortion in EVA based on book value, we can then compare the reported EVA with the true economic profit, which can be calculated from the known true return. The discrepancy between the two figures shows the extent to which EVA is distorted by inflation.

We calculate the standardised EVA the theoretical firm will report under different rates of inflation. In Figure 1 the reported conventional EVA was plotted for five firms that each employ only one type of asset. EVA based on current asset values is shown in Figure 2 for the same five firms.

As in Figure 1, each of the firms has a real return of 10 per cent per year and a real cost of capital of 10 per cent per year. The firms therefore all make zero economic profit, and should report an EVA of zero.

Figure 2 shows that all the firms (with the exception of the all current asset firm) report standardised EVA of less than zero. The reported EVA based on current values of assets is still distorted and the distortion increases with increasing rates of inflation. The pattern of the distortion is much clearer than the pattern of distortion in Figure 1 (EVA on book value). The distortion is consistently higher 
for firms using longer life assets, and consistently lower for firms with shorter life assets.

Figure 2 Standardised Economic Value Added (based on replacement value of assets) reported by a firm with a real return of 10 per cent per year and a real cost of capital of 10 per cent per year

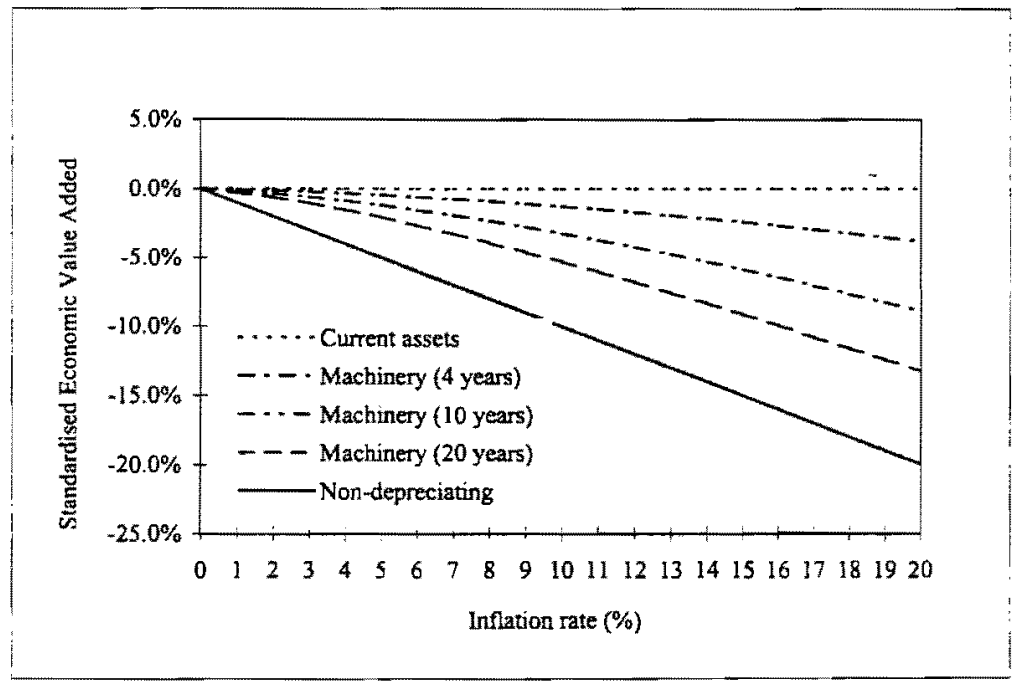

De Villiers (1997: 298) suggests that this consistent pattern of distortion be used to develop an adjusted EVA (AEVA) calculation. The AEVA calculation is based on the current value of assets. Equations (26) and (37) above are used to calculate the required accounting return of the firm (it depends on the firm's cost of capital, the assets employed by the firm, the tax rate, and the inflation rate). The required accounting rate of return is multiplied by the current value of capital employed and the product subtracted from net operating profits after tax to produce the AEVA of the firm. The AEVA provides an estimate of the actual profitability of the firm under inflation.

\section{CONCLUSION}

This paper presents an algebraic model to derive the relationships that were illustrated by means of a numerical example in De Villiers (1997). The results show that reported EVA is distorted even in the absence of inflation. This 
distortion is exacerbated by inflation, and reported EVA cannot be used under inflation to estimate actual profitability.

The paper then calculates a theoretical firm's reported EVA based on the current values of assets employed. It shows that, like conventional EVA, this version of EVA is distorted by inflation. The pattern of distortion is more systematic. EVA based on the current value of assets could form the basis of an adjusted EVA calculation to provide an estimate of the actual profitability of a firm under inflation.

The model presented in this paper is not limited to the study of EVA, but could be adapted to study possible distortions in other accounting figures. This could form the basis of further research.

\section{ENDNOTE}

The author wishes to thank the Editorship for helpful comments and suggestions on an earlier draft of this paper.

\section{REFERENCES}

I DE VILLIERS, J.U. (1997) "The Distortions in Economic Value Added (EVA) Caused by Inflation", Journal of Economics and Business, 49: 285300.

2 HARCOURT, G.C. (1965) "The Accountant in a Golden Age", Oxford Economic Papers 17(1): 66-80.

3 Stewart, G. (1991) The Quest for Value: A Guide to Senior Managers. New York: HarperBusiness. 


\section{APPENDIX}

\section{List of symbols used}

The mathematical model developed in this paper comprises a theoretical firm consisting of a number of projects. The variables used to describe the firm and its projects refer to activity during a year or balance at the end of a year as applicable. $\mathrm{S}$, for example, refers to sales during a year, and $\mathrm{C}$ refers to creditors at the end of a year. Subscripts are used to distinguish between variables relating to individual projects and variables relating to the firm. Double subscripts indicate a project variable; the first subscript relating to the year of the project and the second to the year the project was initiated. $S_{2,3}$, for example, is the project sales during the second year of a project started in year 3 , and $\mathrm{C}_{4,1}$ to the project creditors at the end of the fourth year of a project started in year 1. A single subscript refers to a variable relating to the firm as a whole. $S_{5}$ is the total sales by the firm in year 5 , and $C_{1}$ is the sum of the creditors of the firm at the end of year 1 .

The symbols used in this model are:

$\begin{array}{ll}A & =\text { total assets (book value) at the end of the year } \\ C^{*} & =\text { cost of capital } \\ C & =\text { creditors at the end of the year } \\ C^{A} & =\text { creditors added during the year } \\ C^{B} & =\text { creditors that paid during the year } \\ C A & =\text { current assets at the end of the year } \\ C A^{A} & =\text { current assets acquired during the year } \\ d & =\text { project duration } \\ D & =\text { debtors at the end of the year } \\ D^{A} & =\text { debtors added during the year } \\ D^{P} & =\text { debtors that paid during the year } \\ D A & =\text { depreciable assets at the end of the year } \\ D A^{A} & =\text { depreciable assets acquired during the year } \\ D A^{D} & =\text { depreciation of depreciable assets during the year } \\ E & =\text { accounting profit for the year } \\ E V A & =\text { economic value addded (based on book value of assets) } \\ E V A^{C} & =\text { economic value added (based on current value of assets) } \\ F & =\text { cash flow for the year } \\ I & =\text { inventory at the end of the year } \\ I^{A} & =\text { inventory added during the year } \\ I^{P} & =\text { inventory processed during the year } \\ i & =\text { inflation rate } \\ N A & =\text { non-depreciable assets at the end of the year }\end{array}$


$N A^{A}=$ non-depreciable assets acquired during the year

NOPAT $=$ net operating profit after tax for the year

$r \quad=$ internal rate of return (true rate of retum)

$S \quad=$ total sales during the year

$S E V A=$ standardised economic value added (based on book value of assets)

$S E V A^{C}=$ standardised economic value added (based on current value of assets)

$T=$ income tax payable

$t=$ income tax rate

TS = trading surplus (sales minus cash expenses minus inventory processed)

$V \quad=$ current value of assets

$X=$ cash expenses incurred during the year 